\title{
Statistical Approach towards Point Sources of Groundwater Pollution with Tetrachloroethylene: A Field Study
}

\author{
Kazuhiro Kido, Yasumoto Magara, * Tohru Furuichi* \\ and Masayuki Ikeda $\nmid \ddagger$ \\ Miyagi Prefectural Institute of Public Health, Sendai 983, \\ *Institute of Public Health, Tokyo 108, †Department of \\ Environmental Health, Tohoku University School of \\ Medicine, Sendai 980, and $\ddagger$ Department of Public Health, \\ Kyoto University Faculty of Medicine, Kyoto 606
}

\begin{abstract}
Kido, K., Magara, Y., Furuichi, T. and Ineda, M. Statistical Approach towards Point Sources of Groundwater Pollution with Tetrachloroethylene : A Field Study. Tohoku J. Exp. Med., 1989, 157 (3), 229-239—_Tetrachloroethylene contamination of well water occurred in a primarily residential area. To search for point source(s) of tetrachloroethylene contamination, 91 water samples were collected on three separate occasions from 41 shallow wells scattered in the areas. Three methods of groundwater level analysis (limited to 30 wells), cluster analysis of water quality indicators and contour drawing of tetrachloroethylene concentrations were applied. The former two analyses showed that the pollution took place in aquifers of two terraces out of the three in the polluted area. The contour mapping demonstrated the presence of three spots of suspected pollution sources as the estimated points of highest tetrachloroethylene concentrations. The available information suggested the existence of a facility with possible use of tetrachloroethylene in the past.— contour map; groundwater pollution; point source; tetrachloroethylene
\end{abstract}

In 1982, Environment Agency of the Government of Japan conducted a nation-wide survey of some 1500 wells in 15 cities on groundwater pollution, and made it evident that groundwater (e.g., well water) in major cities was contaminated with tetrachloroethylene (TETRA), trichloroethylene (TRI) and other chlorinated hydrocarbons (Environment Agency 1983). Such problems of groundwater contamination, especially the pollution of drinking water wells, have been serious in many industrialized areas including the U.S. (U.S. Council on Environmental Quality 1981 ; Page 1981) and Western Europe (Quaghebeur and de Wulf 1980 ; Zoeteman et al. 1980; Giger and Schaffner 1981; Trouwborst 1981). Some of these chemicals, e.g. TETRA, are known to be animal carcinogens

Received December 14, 1988 ; revision accepted for publication February 19, 1989.

Requests for reprints should be addressed to : Prof. M. Ikeda, Department of Public Health, Kyoto University Faculty of Medicine, Kyoto 606, Japan. 
(National Cancer Institute 1977; Mennear et al. 1986; National Toxicology Program 1986). It is also known through experiences that the location of pollution source is generally vague and the point is identified on limited occasions (Environment Agency 1986), while removal of pollutants from groundwater is energy-consuming practice (Dyksen and Hess 1982 ; Wang et al. 1985).

In the present study, statistical approaches are applied to a case of groundwater pollution with tetrachloroethylene, and locations of most suspicious point source are estimated. The approaches are described in this article.

\section{Materials and Methods}

\section{The study area}

The study area is $1.4 \mathrm{~km}$ and $1.0 \mathrm{~km}$ long in east-west and north-south directions, respectively, with a space of about $1 \mathrm{~km}^{2}$. The area is primarily a residential area with a population density of about 14,900 persons $/ \mathrm{km}^{2}$ (Sendai City 1987 and 1988), but also rich in shops and stores. No large factories, however, are located in the area. Both drinking water supply system and sewage system were established in 1925 and 1965-1966, respectively (Sendai City 1935 and 1965). In addition, wells, mostly privately-owned shallow ones, are also scattered throughout the area and the well water is employed primarily for non-drinking purpose.

The area consists of three river terraces on the west bank of the River Hirose (Miyagi prefecture 1982) with an inclination from the highest level in the east, a second highest in the north-west and a low level in the west (Fig. 1). Geologically, terrace sediments of Quaternary Diluvium epoch pile on the Kameoka Layer of Tertiary Pleiocene epoch. The

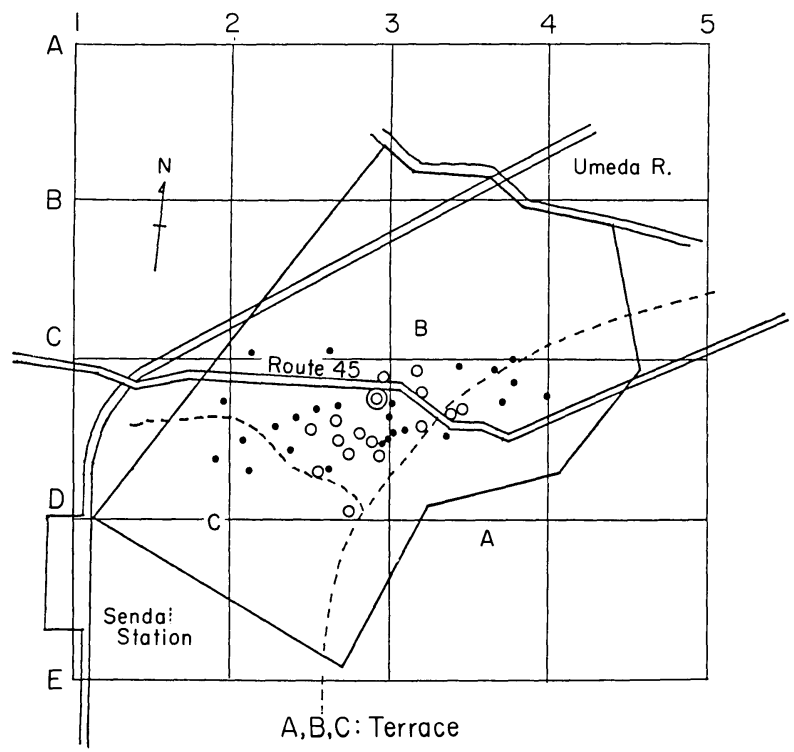

Fig. 1. Location of wells in the study area. Each dot (41 in total) indicates the location of well examined. Open circles show the 16 wells studied 3 times, and the double circle demonstrates the well of the highest TETRA concentration. 


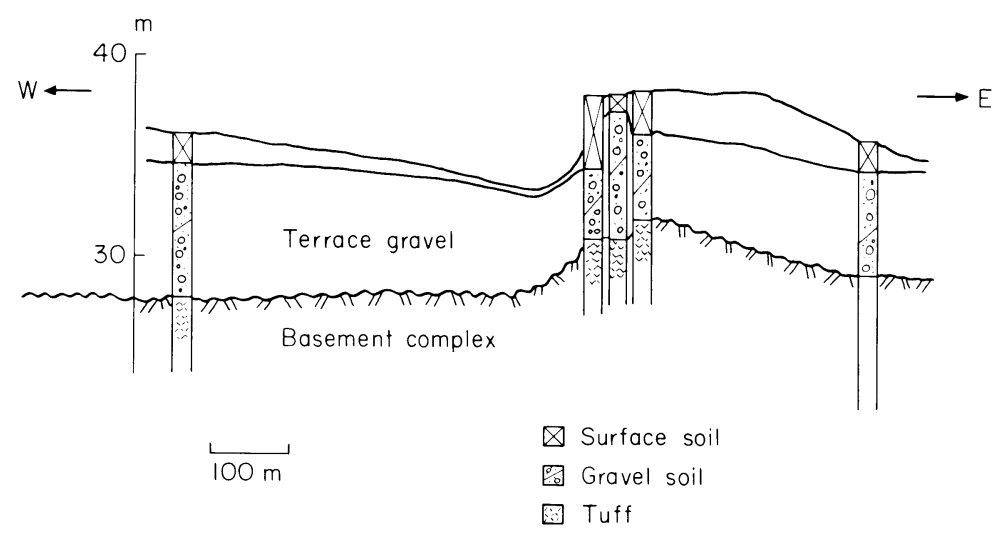

Fig. 2. Geological structure of the ground. The figure is constructed from the data of Miyagi prefecture (1985b). The vertical axis shows the height from the sea level.

geological layers in the area (Fig. 2) are in the order of (from surface to the depth) surface soil (1-2 $\mathrm{m}$ deep), gravel layer (the 3-7 $\mathrm{m}$ deep aquifer; Diluvium epoch pile) and the basement of tuff (Kameoka Layer) as shown by ground boring.

\section{Water level measurements}

The measurement was made on three separate occasions with a hydrograph (Model NP; Kasuga Denki Co., Tokyo). The wells available for the measurement were only of holetype, and limited both in number and in occasion, i.e., 15 wells each in the March 1984, January 1986 surveys (Fig. 2). The March 1984 data are cited from Miyagi prefecture (1984).

\section{Sampling and analyses of water}

Water samples were collected from a total of 41 wells (for locations, see Fig. 1) in August and December, 1983 and January, 1984. The number of wells and well water samples, the number of samples analyzed for TETRA are summarized in Table 1. All wells were shallow wells with less than $10 \mathrm{~m}$ in depth as confirmed at interviews with well owners, and this finding is in agreement with the geological structure of the area (Fig. 2). Each sample water was taken in a 200-ml distilled water-rinsed glass bottle (with no air space in the bottle), ice-chilled for transportation and storage, and analyzed within $24 \mathrm{hr}$ after sampling. The absence of residual chlorine was confirmed by the o-toluidine method (Japan Waterworks Association 1978).

Analysis for low boiling point chlorinated hydrocarbons $(\mathrm{LBCH})$ was conducted by a national standard method (Ministry of International Trade and Industry 1981). In practice, $\mathrm{LBCH}$ in $100 \mathrm{ml}$ sample water was extracted into $10 \mathrm{ml} n$-hexane, and the extract (2 $\mu 1$ /injection) was subjected to a ECD-GC analysis for TETRA, TRI, 1, 1, 1-trichloroethane, carbon tetrachloride and chloroform. The GC (Hitachi Model 163 with ${ }^{63} \mathrm{Ni}-\mathrm{ECD}$ ) was equipped with two glass columns [ $3 \mathrm{~mm}$ in inner diameter and $3 \mathrm{~m}$ in length, one packed with $20 \%$ Silicon DC 550 on Chromosorb WAW DMCS (60-80 mesh) and the other with $25 \%$ Silicon GE Versilb F 50 on Chromosorb WAW DMCS (60-80 mesh)]. The columns were heated at $80^{\circ} \mathrm{C}$, and both injection ports and detectors at $150^{\circ} \mathrm{C}$. Carrier gas, $\mathrm{N}_{2}$, was allowed to flow at $50 \mathrm{ml} / \mathrm{min}$. Under the conditions employed, the detection limits for TETRA, TRI, 1, 1, 1-trichloroethane, carbon tetrachloride and chloroform were 0.2, 0.5, 0.2, 0.05 and $0.5 \mu \mathrm{g} /$ liter, respectively, when the signal/noise ratio was set at 2 . Analyses for other items were conducted by the conventional methods for analyses of drinking water 
(Japan Waterworks Association 1978) and industrial effluents (Ministry of International Trade and Industry 1981).

\section{Statistical analysis}

Cluster analysis was conducted with a NEC 2200 personal computer. Well water level contours were drawn with a computer program 'SIGNAS'. Contours of TETRA levels in well water were drawn after the method of Isobe (1971) utilizing a NEC ACOS-650 computer and a program KUDO/CONTR/S/MAN. The results were depicted in a map with a hypothetical grid of a $500 \mathrm{~m}$ distance between two grid lines.

\section{Results}

\section{Water levels}

A preliminary analysis disclosed that the water levels in a monitoring station well did not differ between two 31-day periods of March 1984 and January 1986 (data not shown). Thus, the water levels on the two survey occasions were combined for contour drawing. The results are depicted in Fig. 3. It is evident that the level was highest (34 m over the sea level) near the Point [3, D] (i.e., the cross of Line 3 and Line D) and gradually lowered toward two points of $[1, \mathrm{E}]$ and $[5, \mathrm{~B}]$.

\section{Cluster analysis of water quality items}

Water quality as evaluated in terms of drinking water criteria excluding LBCH (Japan Waterworks Association 1978) fit well with criteria of all items except that nitrate-nitrite $\left(\mathrm{NO}_{3}{ }^{-}+\mathrm{NO}_{2}{ }^{-}-\mathrm{N}\right)$ nitrogen level was as high as 7.9-10.4 $\mathrm{mg} /$ liter as GM throughout the three studies. The data on 6 water quality items

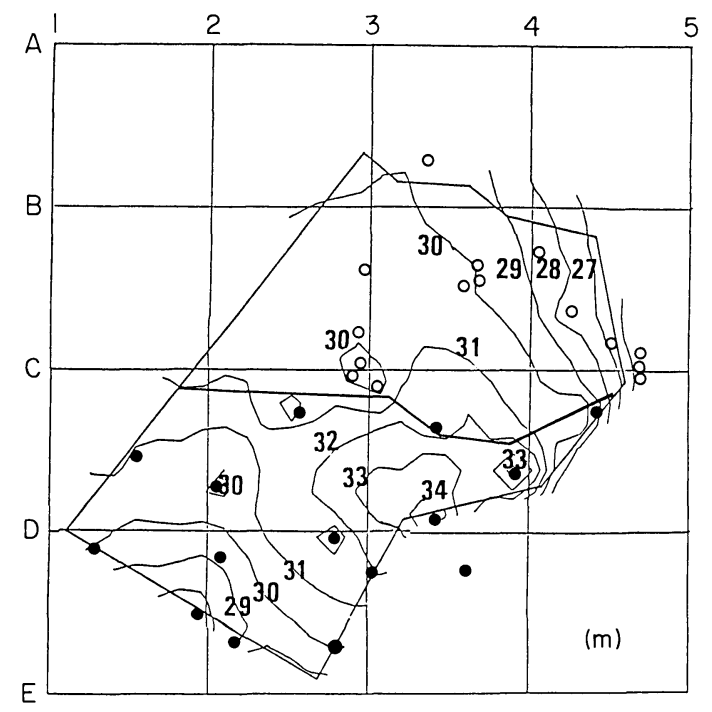

Fig. 3. Groundwater level contour map. Circles indicate the locations of wells studied. Solid ones for March 1984 and open ones for January 1986. 


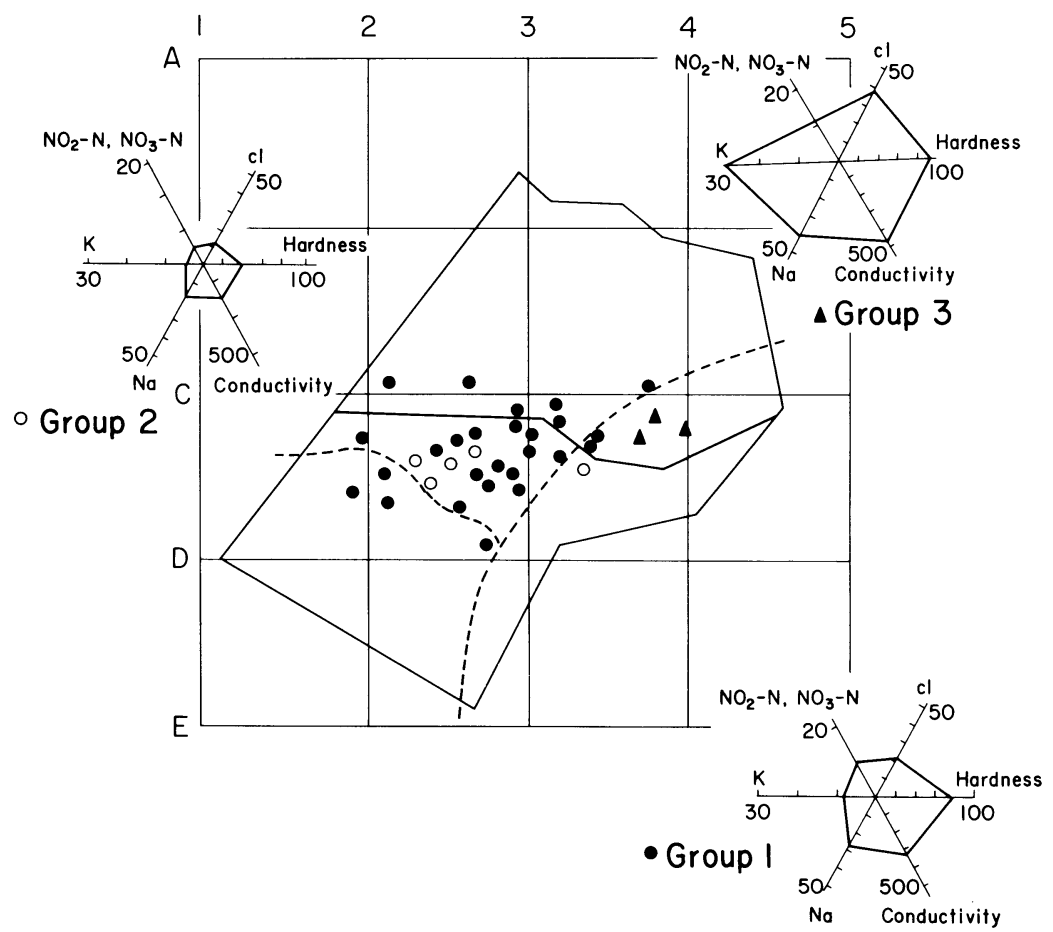

Fig. 4. Results of cluster analysis. Symbols indicate the results of cluster analysis, i.e., solid circles, open circles and triangles for the wells of Groups 1, 2 and 3 , respectively. The polygons at the corners show the characteristics of the three groups. The thick line in the middle shows Route 45.

of $\mathrm{NO}_{3}^{-}+\mathrm{NO}_{2}^{-}-\mathrm{N}, \mathrm{Cl}^{-}$, hardness, $\mathrm{Na}^{+}, \mathrm{K}^{+}$, and electroconductivity were subjected to cluster analysis to identify aquifers from which well water was available. Wells examined in December 1983 study were classified into three groups of 1,2 and 3 as depicted in Fig. 4 ; characteristics of the three groups are also shown in polygons in Fig. 4. The polygons for Group 1 and Group 2 are similar to each other except that the levels in Group 1 were almost twice as high as the counterpart values in Group 2. Group 3 was characteristic in high $\mathrm{K}^{+}$content. The August 1983 and January 1984 data gave essentially the same results, although the data were limited in the August 1983 study so that the clustering into three groups were less marked. It is evident in Fig. 4 that Group 3 wells are clearly separated from wells of other two groups whereas the wells in Groups 1 and 2 are geographically inseparable. Comparison of Fig. 4 with Fig. 3 disclosed a marked agreement between water level grouping and results of cluster analysis. Namely, Group 3 wells located in the area where the water levels were high. The lack of high $\mathrm{K}^{+}$contents in Groups 1 and 2 wells (in which the water levels were lower) suggests that the aquifer for Group 3 wells does not foster the aquifers for Groups 1 and 2 wells. 
TABle 1. Number of samples in well water analyses

\begin{tabular}{lcccc}
\hline Date of survey & $\begin{array}{c}\text { No. of wells } \\
\text { studied }\end{array}$ & \multicolumn{2}{c}{$\begin{array}{c}\text { No. of samples for } \\
\text { TETRA determination }\end{array}$} & \multirow{2}{*}{$\begin{array}{c}\text { No. of samples } \\
\text { for studies on } \\
\text { other items }\end{array}$} \\
\cline { 3 - 4 } & 23 & $<\mathrm{ND}^{a}$ & $\geq \mathrm{ND}^{b}$ & \\
\hline August 1983 & 33 & 29 & 2 & 23 \\
December 1983 & 35 & 31 & 4 & 33 \\
January 1984 & & 4 & 35 \\
\hline
\end{tabular}

${ }^{a}$ Greater than the detection limit of $0.2 \mu \mathrm{g} /$ liter.

${ }^{b}$ Equal to or less than the detection limit.

Chlorinated hydrocarbons in well water

In total, 91 water samples were obtained from the 41 wells in three occasions of the survey (Table 1). The TETRA levels exceeded the provisional drinking water guideline $(10 \mu \mathrm{g} /$ liter; Ministry of Health and Welfare 1984) in water samples from 25 wells out of 41 . The geometric mean TETRA concentrations (GM) [geometric standard deviation (GSD) in parenthesis] : number of samples was $1.27 \mu \mathrm{g} /$ liter (1.011) : 23, $0.94 \mu \mathrm{g} / \operatorname{liter}(1.200): 33$, and $0.92 \mu \mathrm{g} / \operatorname{liter}(1.129)$ : 35 (ND was taken as if it were half the detection limit or $0.1 \mu \mathrm{g} /$ liter for calculation of GM and GSD), with the excess ratio of $65.2 \%, 60.8 \%$ and $54.2 \%$ (in the order of time sequence of three survey occasions), respectively. When the locations of wells polluted heavily with TETRA were superimposed in Fig. 4, it was evident that all contaminated wells were either in Group 1 or in Group 2, whereas none of such was found in Group 3. In contrast, no levels of TRI, 1, 1, 1-

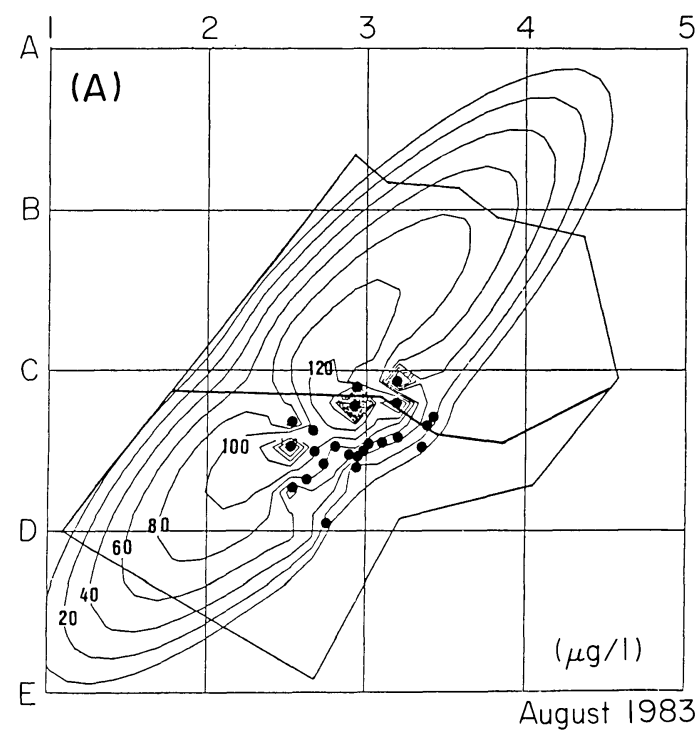



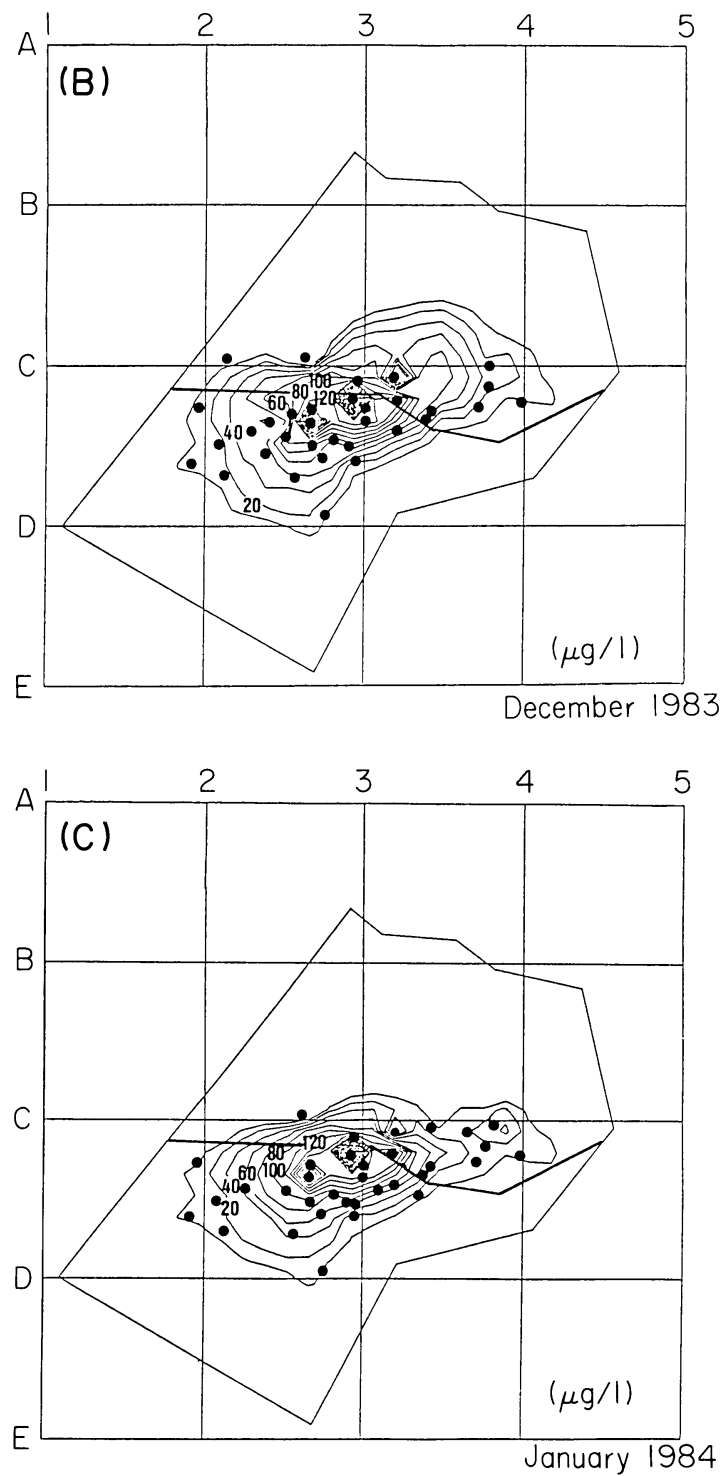

Fig. 5. Contour maps for TETRA concentrations. Contours were drawn with the data obtained in (A) August 1983, (B) December 1983 and (C) January 1984. Each dot in the maps represents a well investigated. The thick line in the middle shows Route 45 .

trichloroethane, carbon tetrachloride or chloroform exceeded the guidelines of 30 , 300 (set by Ministry of Health and Welfare 1984), 3 or $30 \mu \mathrm{g} /$ liter (proposed by World Health Organization 1984), respectively. The results of computermediated contour drawing with three data sets obtained in August 1983, December 1983 and January 1984 are depicted in Fig. 5A, B and C. The maps were essentially the same in the sense that three foci of high TETRA concentration 
were identified and that the three foci located at the same sites (i.e., near the point of $[3, \mathrm{C}]$, and upper right and lower left to that point), despite that the wells studied were not identical and varied to some extent in each study. In the August 1983 study, the lack of study wells upper-left to the three foci inevitably made the contours rather widely distributed, whereas a few wells (especially those with low TETRA levels) were supplemented in the December 1983 and January 1984 studies to make the foci more sharp.

The TETRA levels on the three occasions was highest in the water samples from the same well (shown with a double circle in Fig. 1) and the concentrations were 390, 480 and $492 \mu \mathrm{g} /$ liter, respectively. Comparison of TETRA levels in 16 wells that were studied on every three occasions (i.e., in August 1983, December 1983 and January 1984) disclosed that the levels were essentially unchanged; the difference between August 1983 and December 1983 data, and between December 1983 and January 1984 data were both insignificant $(p>0.10)$ as assayed by paired $t$-test, suggesting that the pollution with TETRA was persisting. The GM (GSD) of TETRA levels in the 16 wells on the three occasions were $18.3 \mu \mathrm{g} /$ liter (11.00), $25.0 \mu \mathrm{g} /$ liter (8.21) and $21.7 \mu \mathrm{g} /$ liter (8.66), respectively.

\section{Search for possible source(s) of pollution}

When factories with possible use of TETRA were sorted in a regional factory list (Miyagi prefecture 1985a), 9 dry-cleaning shops and 1 auto-repair shop were found, among which it was possible in the 2 dry-cleaning shops to identify the use of TETRA. Effluent was properly treated to remove TETRA contamination and dry-cleaning residue was taken out also properly so that the possibility as the point source of pollution was considered very remote. It should be added that there had been a factory in the vicinity of the three foci given in Fig. 5 and the factory had very probably been working with TETRA. No detailed information was, however, available on this factory or any other factories active only in the past but no longer in operation at the time of the present study.

\section{Discussion}

The first step in the management of groundwater pollution is apparently the identification of pollution source(s) with expectation of the removal. The pollution of groundwater can be readily demonstrated by the analysis for pollutant(s) in well water suspected of pollution, and the geographic extent of the pollution can be also estimated, but the location of the pollution source is hardly identified in many cases (Sayato et al. 1983 ; Environment Agency 1986).

In one case of pollution with TRI in which the point source was successfully located, the TRI levels in several contaminated wells were geographically compared to reach the area of highest TRI concentration. Ground boring for additional groundwater samples at 12 sites finally pin-pointed the soil impregnated with TRI at the level as high as $6,600 \mathrm{mg} / \mathrm{kg}$ soil (Environment Agency 1986). In another 
case in which TETRA was detected in tap water, a city water supply system was polluted because one out of three wells (which in combination were the partial source of city water supply) was contaminated with this chemical. The survey of aquifer upstream of the contaminated well led to the discovery of a location where TETRA/water emulsion was detected; the place was in the backyard of a dry-cleaning facility (Giger and Molnar-Kubica 1978). Thus, it is possible to deduce that the approaches employed were empirical and not necessarily systematic.

In the present study, three systematic approaches were employed for the analysis of pollution with TETRA, i.e., water level comparison, cluster analysis of water quality indicators and contour drawing of $\mathrm{LBCH}$ especially TETRA. The former two methods were effective to identify the polluted aquifers but not sensitive enough to indicate the location of the suspected source.

The contour mapping approach was clearly valid in the present study to estimate the location of the point source (Fig. 5). This method was first applied to examine possible transport of pollutants from a solid waste landfill (DeWalle and Chian 1981) or a wastewater infiltration site (Bedient et al. 1983). Thus, DeWalle and Chian (1981) could demonstrate the migration of organics and inorganics through leaching from the solid waste due to infiltrating rainwater to the areas downstream of the landfill. In the study of Bedient et al. (1983), they found a close agreement in contours of groundwater levels between the estimates (based on water flow and chloride contaminant transport) and the observed values. The reverse application of contour drwaing was made in the present study. Namely, contours were drawn for the levels of the pollutant, TETRA, to identify the suspicious site as the theoretical point(s) of the highest TETRA concentrations. The well water survey was repeated three times so that the contour analysis could be triplicated. The results are essentially identical to show high reproducibility. Only the insufficiency of information on the TETRA-associated facilities at the suspected site in the past made it difficult to draw a solid conclusion.

One theoretical draw-back will be the discrepancy that the contour mapping method employed in the present study is a horizontal two-dimensional approach whereas the pollutants in the ground should distribute also vertically and therefore three-dimensionally. In practice, however, the water samples are often available only from shallow wells because the number of deep wells is usually limited as in the present case. Thus, the statistical approach developed in the present study is probably worthy of trying especially when the application of the conventional empirical approaches has technical difficulties, although the approach proposed is not omnipotent by any means. No need for sophisticated parameters in estimation is also a practical advantage. 


\section{Acknowledǵments}

The authors are grateful to Mr. T. Takishima, the director of Miyagi Prefectural Institute of Health and Environment, for his generous support to this work.

\section{References}

1) Bedient, P.B., Springer, N.K., Baca, E., Bouvette, T.C., Hutchins, S.R. \& Tomson, M.B. (1983) Groundwater transport from wastewater infiltration. $J$. Environ. Engineering, 109, 485-501.

2) DeWalle, F.B. \& Chian, E.S.K. (1981) Detection of trace organics in well water near a solid waste landfill. J. Am. Water Works Assoc., 73(4), 206-211.

3) Dyksen, J.E. \& Hess, A.F., 3rd (1982) Alternatives for controlling organics in groundwater supplies. J. Am. Water Works Assoc., 74(8), 394-404.

4) Environment Agency, the Government of Japan (1983) 1982 Report on Ground Water Pollution Survey, Water Quality Bureau, Environment Agency, Tokyo. (Japanese)

5) Environment Agency, the Government of Japan (1986) Cases of Anti-Groundwater Pollution Measures in Japan, Japan Water Pollution Association, Tokyo. (Japanese)

6) Giger, W. \& Molnar-Kubica, E. (1978) Tetrachloroethylene in contaminated ground and drinking waters. Bull. Environ. Contam. Toxicol., 19, 475-480.

7) Giger, W. \& Schaffner, C. (1981) Groundwater pollution by volatile organic chemicals. In: Quality of Groundwater, Studies in Environmental Science, Vol. 17, edited by W. van Duijvenbooden, P. Glasbergen \& H. van Lelyveld, Elsevier, Amsterdam, pp. 517-522.

8) Isobe, T. (1971) A program for contour drawing. Aviation and Space Technology Institute Data TM-198, Aviation and Space Technology Institute. (Japanese)

9) Japan Waterworks Association (1978) Tests for Drinking Water Quality, Japan Waterworks Association, Tokyo. (Japanese)

10) Mennear, J., Maronpot, R., Boorman, G., Eustis, S., Huff, J., Haseman, J., McConnell, E., Ragan, H. \& Miller, R. (1986) Toxicologic and carcinogenic effects of inhaled terachloroethylene in rats and mice. In : New Concepts and Developments in Toxicology, edited by P.L. Chambers, P. Gehring \& F. Sakai, Elsevier, Amsterdam, pp. 201210.

11) Ministry of Health and Welfare, the Government of Japan (1984) Provisional Drinking Water Criteria for Trichloroethylene and Other Chemicals. Department of Water Supply and Environmental Sanitation, Ministry of Health and Welfare, Tokyo. (Japanese)

12) Ministry of International Trade and Industry, the Government of Japan (1981) JIS K0102 Tests for Factory Effuent, Japanese Standards Association, Tokoyo. (Japanese)

13) Miyagi prefecture (1982) 1981 Maps for Measures Taken against Land Subsidence, Department of Health and Environment, Miyagi prefecture, Sendai. (Japanese)

14) Miyagi prefecture (1984) Report on Water and Ground Preservaion in Connection with Two-Level Crossing of Senseki Line, Department of Civil Engineering, Miyagi prefecture, Sendai. (Japanese)

15) Miyagi prefecture (1985a) The List of Factories in Miyagi Prefecture, Department of Commerce, Miyagi prefecture, Sendai. (Japanese)

16) Miyagi prefecture (1985b) The Structure of Ground in Miyagi Prefecture, Department Health and Environment, Miyagi prefecture, Sendai. (Japanese)

17) National Cancer Institute (1977) Bioassay of Tetrachloroethylene for Possible Carcinogenicity, NCI-CG Technical Report Series No. 13, U.S. Government Printing Office, Washington DC. 
18) National Toxicology Program (1986) Toxicology and Carcinogenesis Studies of Tetrachloroethylene (Perchloroethylene) in F344/N Rats and B6C3F1 Mice (Inhalation Studies), NTP Technical Report Series No.311, U.S. Government Printing Office, Washington DC

19) Page, G.W. (1981) Comparison of groundwater and surface water for patterns and levels of contamination by toxic substances. Environ. Sci. Technol., 15, 1475-1481.

20) Quaghebeur, D. \& de Wulf, E. (1980) Volatile halogenated hydrocarbons in Belgian drinking waters. Sci. Total Environ., 14, 43-52.

21) Sayato, Y., Nakamuro, K., Ando, M., Ishizuka, M., Sano, H. \& Kashiramoto, F. (1983) Occurrence of volatile chlorinated organic compounds and alteration of chlorinated products in well water in the Tama River Basin. J. Jpn. Soc. Water Poll. Res., 6, 39-45. (Japanese)

22) Sendai City (1935) History of Waterworks in Sendai, Department of Waterworks, Sendai City, Sendai. (Japanese)

23) Sendai City (1965) Sendai City Notice No 60, Department of General Affairs, Sendai City, Sendai. (Japanese)

24) Sendai City (1987) List of Space by Block in Sendai City, Department of General Affairs, Sendai City, Sendai. (Japanese)

25) Sendai City (1988) Statistics of Sendai City, Department of General Affairs, Sendai City, Sendai. (Japanese)

26) Trouwborst, T. (1981) Groundwater pollution by volatile halogenated hydrocarbons, source of pollution and methods to estimate their reference. Sci. Total Environm., 21, 41-46.

27) U.S. Council on Environmental Quality (1981) Contamination of Ground Water with Toxic Chemicals, Executive Office of the President Council on Environmental Quality, Washington, D.C.

28) Wang, T.C., Lenahan, R., Kanik, M. \& TenEyck, J. (1985) The removal of trichloroethylene contaminated groundwater at Vero Beach, Florida. Arch. Environm. Contam. Toxicol., 14, 719-723.

29) World Health Organization (1984) Guideline for Drinking Water Quality, World Health Organization, Geneva.

30) Zoeteman, B.C.J., Harmsen, K., Linders, J.B.H.J., Morra, C.F.H. \& Slooff, W. (1980) Persistent organic pollutants in river water and ground water of the Netherlands. Chemosphere, 9, 231-249. 